\title{
The role of magma buoyancy on the eruption of lunar basalts
}

\author{
Mark A. Wieczorek ${ }^{a, *}$, Maria T. Zuber ${ }^{a}$, Roger J. Phillips ${ }^{b}$ \\ a Department of Earth, Atmospheric and Planetary Sciences, Massachusetts Institute of Technology, 54-520, \\ Cambridge, MA 02139, USA \\ b Department of Earth and Planetary Sciences, Washington University, One Brookings Dr., Box 1169, St. Louis, MO 63130, USA
}

Received 13 July 2000; received in revised form 13 November 2000; accepted 20 November 2000

\begin{abstract}
It has long been recognized that mare basalts on the Moon are preferentially located both on the Earth-facing hemisphere and within large impact basins. A popular model that accounts for this observation assumes that these magmas were denser than the lunar crust, that they accumulated at the crust-mantle interface, and that eruptions occurred only when this magma chamber became overpressurized. In this paper, we re-evaluate this model and argue that it is not consistent with the available data nor with models of dike propagation. As an alternative hypothesis, we propose that magma buoyancy is the predominant factor that determines whether mare basalts erupt at the surface or form crustal intrusions instead. We have computed the densities of mare basaltic magmas and find that some are, in fact, less dense than the Moon's upper anorthositic crust. Based on the widely accepted view that the lunar crust becomes more mafic with depth, we also show that all mare basaltic magmas should be less dense than the lower portion of the crust. Thus, if the upper anorthositic crust was regionally removed by an impact event, then any mare basaltic magma could have risen to the surface there based on buoyancy considerations alone. In support of this model, we note that mare basalts are indeed found wherever geophysical crustal thickness models predict the upper crust to be absent. Furthermore, many of the basalts that erupted within the anorthositic highlands are predicted to be less dense than the underlying crust based on remote sensing data. The high titanium flows within Oceanus Procellarum are somewhat problematical to our model in that an anorthositic crust is predicted to be present beneath them. Using results from recent lunar thermal models, we suggest that these magmas may have overcome their negative buoyancy in the crust by possessing superliquidus temperatures. If magma buoyancy does indeed control whether or not a basaltic eruption will occur, then this implies that the quantity of magma produced beneath the South Pole-Aitken basin was about 10 times less than that of the nearside. (C) 2001 Elsevier Science B.V. All rights reserved.
\end{abstract}

Keywords: Moon; volcanism; magmas; buoyancy; magma transport

\section{Introduction}

Two geologic processes that have modified the

\footnotetext{
* Corresponding author. Tel.: +1-617-452-2304; Fax: +1-617-258-9697; E-mail: markw@quake.mit.edu
}

lunar surface are impact cratering and mare volcanism. Whereas impact cratering is a spatially random process, the maria are far from being uniformly distributed. Images of the Moon's farside clearly show that more than $90 \%$ of the lunar lava flows by area are located on the Earth-facing hemisphere. With the exception of the large region spanned by Oceanus Procellarum, most of 
these basaltic flows are associated with large impact basins. A major question concerning lunar evolution is whether this distribution of basaltic volcanism is a result of spatial variations in partial melting of the lunar interior, or is simply the result of some magma transport process that has inhibited the eruption of basalts on the farside.

During the Apollo missions the topography of the Moon was measured from orbit along two roughly equatorial swaths. These data showed that the elevation of the nearside was on average about $2 \mathrm{~km}$ lower than that of the farside with respect to the Moon's center of mass [1]. If this topography was compensated by an Airy mechanism, then this observation would imply that the nearside crust is at least $10 \mathrm{~km}$ thinner than that of the farside. Furthermore, as a result of the low elevations associated with the nearside impact basins, the thickness of the crust in these regions should be less than the nearside average. The coincidence in regions that were inferred to have a thinned crust and the distribution of basaltic eruptions suggested to many that these two phenomena were genetically related.

Kaula et al. [1], Runcorn [2], and Solomon [3] were the first to argue that the apparent correlation between crustal thickness and mare volcanism could be explained using the concept of 'hydrostatic head'. In these models, a force balance between the weight of a column of magma and the lithostatic pressure at the mare source determines whether a basaltic dike will extend to the surface or not. Assuming that lunar basaltic magmas were in general denser than the crust, and that a single dike could extend from the surface to the mare source, these models predicted that basaltic eruptions should only have occurred at low elevations where the crust is presumably thinned.

As magmatic processes on Earth became better understood with time, it became increasingly apparent that magma buoyancy plays a major role in the dynamics of magma transport and storage. Many have argued that the Earth's crust acts as a density filter allowing only those magmas that are less dense than the crust to erupt (e.g., [4,5]). The role of magma buoyancy was further shown by Ryan [6] and Walker [7] to control the depth at which magma chambers form within the Earth's crust. They argued that magma is stored at a level in which it is neutrally buoyant (the 'neutral buoyancy horizon'), and that as a result of a highly fractured near surface layer this level is usually located at only a few kilometers depth. Bladed dikes on the flanks of Kilauea and Krafla have been shown to propagate along the neutral buoyancy horizon (e.g., [6,8]), and theoretical and experimental models [8-10] have confirmed this general behavior of magma transport and storage. The neutral buoyancy concept has also been successfully applied to the Martian volcano Olympus Mons [11].

Head and Wilson [12] modified the previous lunar hydrostatic head models to take into account the concept of neutral buoyancy. Assuming that mare basaltic magmas were denser than the lunar crust, they postulated that mantle-derived partial melts would buoyantly rise through mantle and accumulate at the crust-mantle interface. On the Moon, this interface has been seismically determined to be at a depth of about $60 \mathrm{~km}$ beneath the Apollo 12 and 14 sites [13]. They showed that if the crust were isostatically compensated, these magmas would only be able to erupt at the surface if their associated magma chamber became overpressurized. The magnitude of this requisite excess pressure was shown to increase with increasing crustal thickness, thus making it more likely for volcanic eruptions to occur where the crust is thin.

Though these early models could explain the apparent correlation between the distribution of mare volcanism and the then available elevation and crustal thickness constraints, data obtained from the Clementine and Lunar Prospector spacecraft have shed considerable doubt upon these models. Altimetry data from the Clementine mission have shown that the lowest lunar elevations occur within the farside South Pole-Aitken basin [14], and geophysical crustal thickness modeling $[15,16]$ has shown that the crust there is thinner than over much of the nearside. Though there are a few mare ponds sparsely distributed throughout this basin (e.g., [17,18]), if crustal thickness and elevation were the only factors controlling the eruption of mare basalts, then this basin should 
have been expected to have been completely resurfaced by lava flows [19].

Gamma-ray data from the Lunar Prospector mission have alternatively suggested to some that the distribution of mare volcanism may have more to do with spatial variations in magma production than with magma transport processes. Data from this spacecraft show that the surface abundances of heat-producing and incompatible elements (i.e., KREEP) are highly concentrated in the Oceanus Procellarum and Mare Imbrium regions of the Moon [20]. Based on this and other observations, it has been argued (e.g., [21-24]) that this region of the Moon is a unique KREEP-rich geochemical province (i.e., the 'Procellarum KREEP Terrane'). Wieczorek and Phillips [24] noted that the distribution of mare basalts and the confines of this province are highly correlated, and by utilizing a simple conductive thermal model they showed that the enhanced heat production of this region was more than sufficient to partially melt the underlying mantle.

Thermal models that take into consideration the convection of distinct chemical layers that may have existed within the Moon also highlight the possible importance of spatial variations in magma production rates within the lunar interior. Zhong et al. [25] showed that a degree-1 upwelling of KREEP- and ilmenite-rich magma ocean cumulates could have caused the deep mantle to melt in only one hemisphere. Conversely, Parmentier et al. [26] showed that a degree-1 downwelling of KREEP- and ilmenite-rich magma ocean cumulates could have concentrated heatproducing elements on one hemisphere of the Moon, giving rise to a hemispheric asymmetry in partial melting of the mantle.

Though these recent thermal models all propose that spatial variations in magma production may be important for explaining the distribution of mare volcanism, none of these models have addressed how magma is transported from the mare source to the surface. At present it is unknown whether magma transport processes or magma production is the dominant factor in controlling the eruption of mare basalts on the Moon. Since magma buoyancy is known to play a dominant role in controlling the eruption of lava on Earth, we suspect that this factor will play an important role in lunar magmatic processes as well. In this paper we test the hypothesis that magma buoyancy is the predominant factor that controls whether basaltic magmas will erupt on the Moon or form crustal intrusions instead.

In Section 2 of this paper we first argue that the traditional hydrostatic head hypothesis for controlling the eruption of mare basalts is inconsistent with the available lunar data and current models of dike formation and propagation. In Section 3 we compute the liquidus densities of mare basaltic magmas and discuss the structure and composition of the lunar crust. We then show that the lunar volcanic record is consistent with the hypothesis that magma buoyancy is the predominant factor in determining whether a basaltic magma will erupt at the surface. In Section 4 we discuss some of the implications of this model.

\section{Evidence against the hydrostatic head hypothesis}

\subsection{Crustal thickness and elevation}

The main prediction for all variations of the hydrostatic head hypothesis is that volcanic eruptions should preferentially occur either at low elevations or where the crust is thin. (If the crust is compensated by an Airy mechanism then elevation and crustal thickness are linearly related to each other.) We test this prediction using the distribution of mare basalts as mapped by Wilhelms [17].

In Fig. 1 the elevation of the lunar surface [27] referenced to the lunar geoid [28] is plotted for those regions of the Moon where volcanic flows are present. (When referenced to the geoid, basalt flow directions accurately track elevation changes.) This image emphasizes the ubiquity of flows within the nearside basins and Oceanus Procellarum, and the scarcity of flows within the Australe and South Pole-Aitken basins. Using the data from Fig. 1, the fraction of lunar area that is covered by lava flows is plotted as a function of 


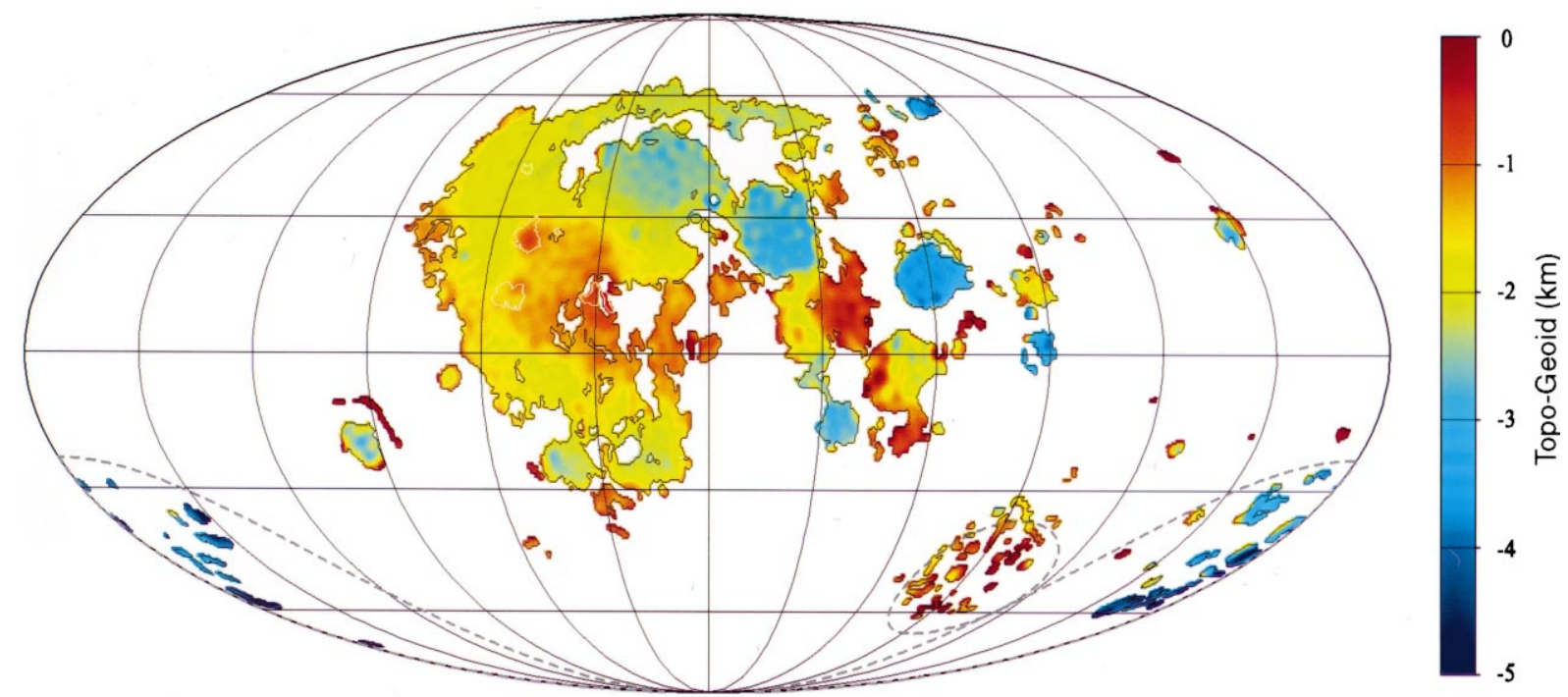

Fig. 1. Elevation of the maria referenced to the lunar geoid. The volcanic provinces of Wilhelms [17] (e.g., the Aristarchus Plateau, Marius Hills, Rümker Hills, and a region just west of Copernicus) are outlined in white, and the approximate confines of the South Pole-Aitken and Australe basins are delineated by dashed lines. Center meridian is $0^{\circ}$ longitude and the map is an equal-area Mollweide projection.

elevation in Fig. 2. Though no basaltic flows are found at the highest elevations (between 2 and $8 \mathrm{~km}$ ), the paucity of basaltic eruptions at the lowest lunar elevations (primarily within the South Pole-Aitken basin) is clearly an inconsistency with the hydrostatic head hypothesis.

To test the putative connection between basaltic volcanism and crustal thickness, we plot the fraction of area covered by lava flows as a func-

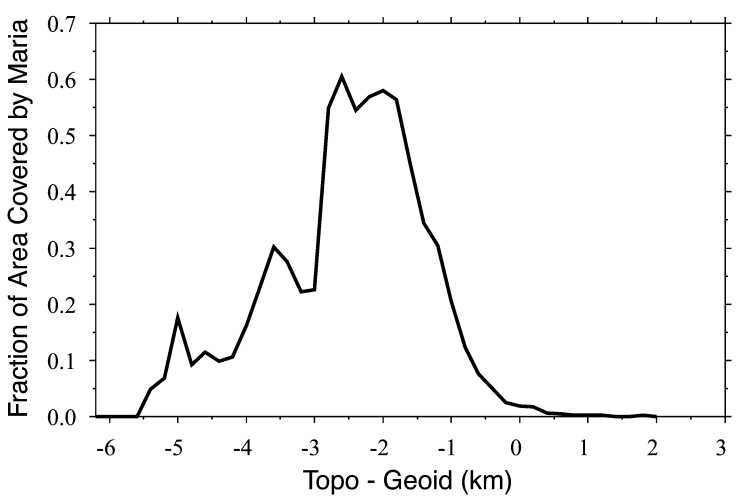

Fig. 2. The fraction of lunar area covered by mare basalts as a function of elevation. Elevations on the Moon range from about -6 to $8 \mathrm{~km}$. tion of crustal thickness in Fig. 3. Here we have used the single-layer crustal thickness model of Wieczorek and Phillips [16] updated using the 100-degree Lunar Prospector gravity field [28]. This plot shows that lava flows are highly prevalent where the crust is thinnest (less than $30 \mathrm{~km}$ ). However, this plot also illustrates that there is a paucity of lava flows within the South Pole-Ait-

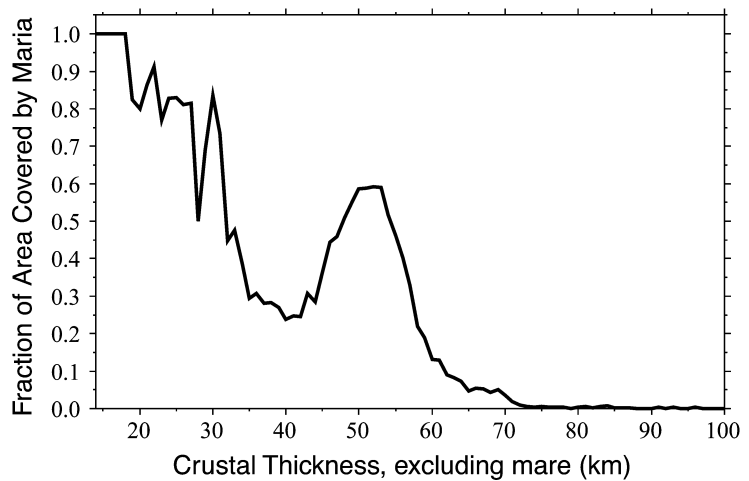

Fig. 3. The fraction of lunar area covered by mare basalts as a function of crustal thickness. The thickness of mare flows has been subtracted from the crustal thickness determinations. The crustal thickness of the Moon in this model ranges from about 6 to $156 \mathrm{~km}$. 
ken basin where the crust is about $40 \mathrm{~km}$ thick, and a relative abundance of flows within Oceanus Procellarum where the crust is comparatively thicker $(\sim 50-60 \mathrm{~km})$. Though this observation suggests that crustal thickness may somehow influence the conditions necessary for basaltic eruptions to occur on the Moon, crustal thickness by itself cannot solely explain the global distribution of mare basalts.

\subsection{The depth of the mare source}

Assuming that the mare basaltic magmas were generally denser than the Moon's crust, it has been suggested that the lithostatic pressure at the mare source could have forced these magmas to the surface [1-3,29]. Assuming this hypothesis to be correct, Solomon [3] showed that the maximum height at which mare basalts erupted could be used to constrain the maximum depth of the mare source. This was accomplished by performing a simple force balance between the Moon's reference hydrostatic pressure at the depth of the mare source and the pressure due to the weight of a magma column extending from the source to the surface.

Assuming that this version of the hydrostatic head hypothesis is correct, we have performed a similar calculation using extreme values for all parameters in order to maximize our computed depth of the mare source. The reference lunar hydrostatic pressure as a function of depth was computed assuming that the Moon possesses a $67 \mathrm{~km}$ thick crust of density $2900 \mathrm{~kg} / \mathrm{m}^{3}$, a $430 \mathrm{~km}$ radius iron core of density $7300 \mathrm{~kg} / \mathrm{m}^{3}$, and an average mantle density of $3335 \mathrm{~kg} / \mathrm{m}^{3}$ (constrained by the known lunar mass). In computing the pressure dependence upon the density of the mare basaltic magma column, a secondorder Birch-Murnaghan equation of state was used with a reference liquidus density of $3028 \mathrm{~kg} /$ $\mathrm{m}^{3}$ and an isothermal bulk modulus of $17.4 \mathrm{GPa}$ (the evaluation of these parameters is discussed separately in Section 3.1). Using $1.8 \mathrm{~km}$ as the maximum elevation at which mare basaltic magmas have erupted, this procedure implies that the mare source is no more than $143 \mathrm{~km}$ below the surface.
Experimental petrologic studies of the mare basalts give an independent estimate of their source depth. Using the assumption that these magmas were multiply saturated in olivine and pyroxene in their source and that their compositions represent primary melts, the depths of origin of these basalts have been found to lie in the range of $\sim 100$ and $250 \mathrm{~km}$ (see the data compiled in [30]). However, if these magmas differentiated on their way to the surface, or if they are genetically related to the picritic glasses, then the mare source could be much deeper than this range (e.g., [30]). If the mare source was as deep as $250 \mathrm{~km}$, then this version of the hydrostatic head hypothesis predicts that basaltic eruptions could have occurred at elevations in excess of $6 \mathrm{~km}$. If slightly less restrictive parameters were used in our calculations, then we find that an eruption could have occurred at any elevation. This is in direct conflict with the observation that all mare basaltic eruptions are found at elevations below $2 \mathrm{~km}$.

\subsection{Dike formation and propagation}

Head and Wilson [12] modified the above hydrostatic head hypothesis by recognizing that basaltic magmas would buoyantly rise through the mantle until they encountered a neutral buoyancy horizon. Since these magmas were assumed to be denser than the crust, they would accumulate at the crust-mantle interface about $60 \mathrm{~km}$ below the surface. A basaltic eruption in this model would only occur if the magma chamber became sufficiently overpressurized.

This explanation, however, overlooks the observation that once magma is stored at the neutral buoyancy horizon it will preferentially propagate along this interface (e.g., [6-8]). This occurs simply because a magma must work against gravity when it propagates vertically, whereas little gravitational work is done when it propagates laterally. Lister [9] and Lister and Kerr [10] demonstrated this phenomenon by theoretical and experimental modeling of a growing bladed dike under a given magma production rate. They showed that a dike at the neutral buoyancy horizon does indeed primarily propagate horizontally, but that the dike also grows vertically at a much 
slower rate. Since the neutral buoyancy horizon is typically only a few kilometers below the surface on Earth, they argued that this overshoot could easily lead to the eruption of lava at the surface.

Is it possible that a surface eruption of lunar basalts could occur by a $60-\mathrm{km}$ overshoot of the neutral buoyancy horizon? Using the theoretical formalism outlined in Lister [9] we have chosen extreme parameters that would maximize the likelihood for such an eruption to occur. We have used the maximum effusion rate from Hulme [31] of $6 \times 10^{5} \mathrm{~m}^{3} / \mathrm{s}$ as typifying a constant magma production rate within the bladed dike. The maximum viscosity of mare basaltic magmas was used (28.3 Pa s; see Section 3.1), a density of $3400 \mathrm{~kg} /$ $\mathrm{m}^{3}$ was used for the mantle, and an extremely small density contrast of only $50 \mathrm{~kg} / \mathrm{m}^{3}$ was used between the crust $\left(2900 \mathrm{~kg} / \mathrm{m}^{3}\right)$ and magma $\left(2950 \mathrm{~kg} / \mathrm{m}^{3}\right)$. In this model we find that in order for a dike to overshoot the neutral buoyancy horizon by $60 \mathrm{~km}$ the length of the dike must exceed $1000 \mathrm{~km}$. Using slightly more reasonable parameters yields dike lengths that exceed the circumference of the Moon. Though this dike propagation model does incorporate some simplifying assumptions that may turn out to be incorrect, a $60-\mathrm{km}$ vertical overshoot of the neutral buoyancy horizon, nonetheless, seems improbable.

\section{The role of magma buoyancy}

In this section we test the hypothesis that magma buoyancy is the predominant factor that determines whether mare basaltic magmas will erupt at the surface or form dikes and plutons in the crust instead. We first describe our method for computing the density of mare basaltic magmas. Next, we discuss our current understanding of the density and structure of the lunar crust and show that most basaltic eruptions are consistent with this hypothesis. The basalts of Oceanus Procellarum are somewhat problematical to our model, but we show that these eruptions may be reconciled within the buoyancy hypothesis by taking into account the unique thermal history of this region of the Moon.

\subsection{The density of mare basalts}

In computing the densities of mare basaltic magmas we have used the chemical compositions of the mare basaltic reference suite as tabulated in the BVSP [32]. Liquidus temperatures for these compositions were determined using the technique of Delano [33] and the liquidus densities of these magmas were computed using the partial molar volume data of Lange and Carmichael [34]. The partial molar volumes of $\mathrm{MnO}$ and $\mathrm{Cr}_{2} \mathrm{O}_{3}$ were approximated by their solid oxide molar volumes $[34,35]$. In addition, the isothermal bulk moduli and viscosities of these magmas were determined using the data of Kress and Carmichael [36] and Bottinga and Weill [37], respectively. (Our computed liquidus densities, temperatures, bulk moduli, and viscosities for the mare basaltic reference suite and picritic glasses can be found in the EPSL Online Background Dataset ${ }^{1}$, Tables 1 and 2.)

We plot our computed liquidus densities as a function of titanium and aluminum content in Fig. 4. Though there is not a clear linear relationship between $\mathrm{TiO}_{2}$ content and density, this plot does illustrate that the highest titanium compositions have the highest densities and that those compositions highest in aluminum have the lowest densities. The liquidus densities of the picritic glasses (compositions from [38]) are shown for comparison and they are seen not to differ significantly from their mare basalt counterparts.

Remote sensing data obtained from both Earth and lunar orbiting spacecraft demonstrate that the mare basalts are more compositionally diverse than those present in the Apollo sample collection (e.g., [39]). Near-global concentrations of $\mathrm{FeO}$ and $\mathrm{TiO}_{2}$ have been determined at a relatively high resolution on the Moon's surface [40] and we use this information to constrain the liquidus densities of these basalts. We have performed a linear least-squares fit between the weight percent of $\mathrm{FeO}$ and $\mathrm{TiO}_{2}$ and our computed liquidus densities, and plot the result in Fig. 5. As is seen,

\footnotetext{
${ }^{1} \mathrm{http}: / / \mathrm{www}$. elsevier.nl/locate/epsl; mirror site: http://www. elsevier.com/locate.epsl
} 
there is a very good linear relationship between liquidus density and the weighted combination of $\mathrm{FeO}$ and $\mathrm{TiO}_{2}$. Thus, if the concentration of these two elements can be remotely determined for a lunar lava flow, then its liquidus density can be determined to a good approximation as well.

\subsection{The density and structure of the lunar crust}

The primary reason that hydrostatic head models were advocated as a magma transport process on the Moon is that it was thought that the mare basalts were on average denser than the lunar crust. If the lunar crust were predominantly anorthositic in composition throughout, then this assumption would generally be true. We compute the average feldspathic upper crust to have an unfractured density of $2890 \mathrm{~kg} / \mathrm{m}^{3}$ (using the compositional data of [23]), and as is seen in Fig. 4 many of the mare basaltic magmas are indeed denser than this value. We do note, though, that about a quarter of these basaltic magmas are less dense than the upper crust and that these compositions generally have low titanium or high aluminum concentrations. Thus, some of the mare basalts could have risen to the surface based solely on buoyancy considerations. (The consequences of a low density, brecciated near surface layer will be discussed separately in Section 4.2. We

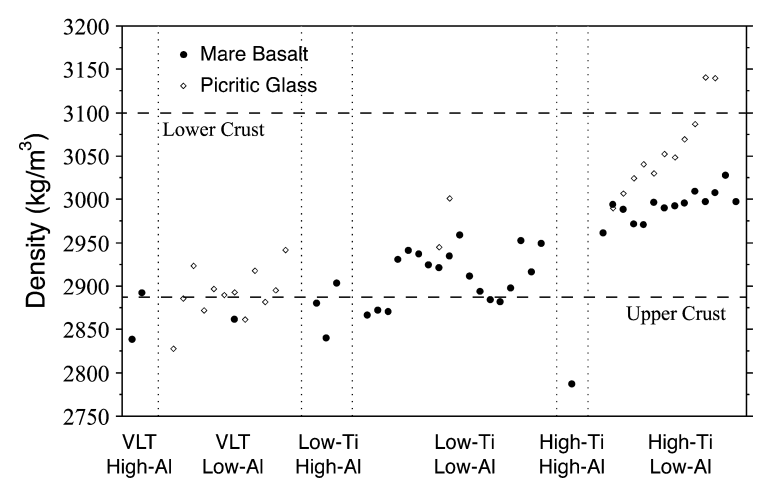

Fig. 4. Plot of the liquidus density of mare basaltic and picritic magmas as a function of composition. The basalts have been grouped into very low titanium (VLT), low titanium, high titanium, low aluminum, and high aluminum subsets, and the titanium content in each group increases to the right. Horizontal lines denote the approximate density of the Moon's upper anorthositic and lower noritic crust.

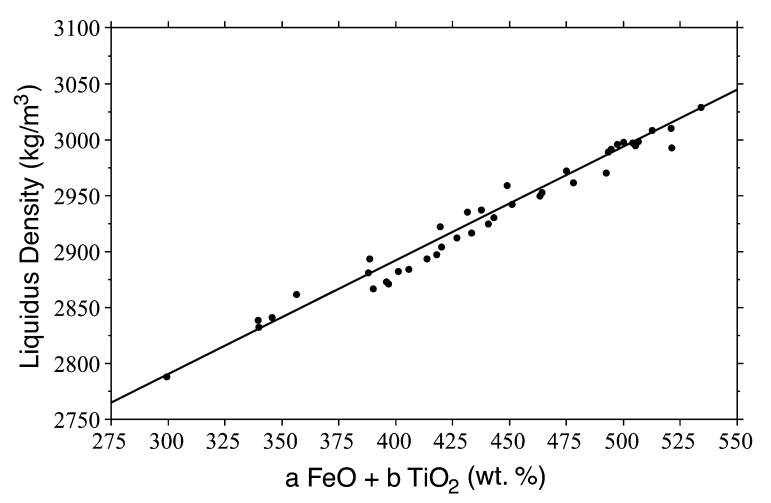

Fig. 5. Plot of the liquidus temperature of mare basaltic magmas as a function of combined weighted concentrations of $\mathrm{FeO}$ and $\mathrm{TiO}_{2}$. A least-squares fit is given by $\rho=a$ $\mathrm{FeO}+b \mathrm{TiO}_{2}+c$, where $a=18.42, b=13.06$, and $c=2490$.

note at present, though, that a bladed dike on the Moon should be able to overshoot such a shallow neutral buoyancy horizon just as it does on the Earth.)

Since the Apollo era it has become increasingly evident that the lunar crust becomes more mafic (and hence denser) with depth (see the summary in [41]). Briefly, the evidence includes the following. (1) A 20-km seismic discontinuity appears to exist within the crust beneath the Apollo 12 and 14 sites (e.g., [13]). (2) The noritic impact melt breccias sampled at the Apollo stations most likely have a deep crustal origin (e.g., [42]). (3) The ejecta blankets of large basins have been shown to be more mafic than average crustal materials (e.g., [43]). (4) The compositions of some central peaks in complex craters are highly noritic or troctolitic (e.g., [44]). (5) Geoid to topography ratios for the lunar highlands suggest some form of density stratification within the crust [41]. And (6) the geophysically derived crustal structure of the South Pole-Aitken basin [16] as well as the composition of this basin's floor (e.g., [45]) suggest that this basin may have excavated into a noritic lower crust.

The above evidence does not unambiguously distinguish between whether the lunar crust is stratified into an upper anorthositic and lower noritic crust, or rather if the crust is vertically zoned between these two compositions. As an end-member scenario, though, Wieczorek and 
Phillips [16] have modeled the thickness of the crust for the case in which the Moon possesses two distinct crustal layers. The thickness of the two layers in this model was constrained by the depth of the Moho and the intracrustal seismic discontinuity at the Apollo 12 and 14 sites. This type of modeling is inherently non-unique, and this study assumed that variations in the Bouguer gravity field are predominantly due to relief along the intracrustal interface. Where variations in the thickness of the upper crust could not fully account for the observed gravity field, the crustmantle interface was allowed to vary as well. The most interesting result of this model is that the upper anorthositic crust is predicted to be absent beneath many of the large impact basins.

Though the exact composition of the lower portion of the Moon's crust is not known, a typical value quoted for its density is about $3100 \mathrm{~kg} / \mathrm{m}^{3}$ (e.g., [41]). As shown in Fig. 4, all mare basaltic magmas (and almost all of the picritic glasses) are less dense than this value. Thus, if the upper anorthositic crust was completely exhumed in an impact event, then any compositional variety of basalt could have risen to the surface there from buoyancy considerations alone. In Fig. 6 we plot those regions of the Moon where the upper anorthositic crust is predicted to be nearly absent (less than $5 \mathrm{~km}$ thick) from the above dual-layered crustal model (updated here using the 100-degree Lunar Prospector gravity field [28]). These areas include the South Pole-Aitken, Orientale, Humorum, Imbrium, Serenitatis, Humboldtianum, Nectaris, Crisium, Smythii, and Moscoviense basins. Isolated regions also occur within Mare Tranquillitatis, Nubium, Frigoris, Fecunditatis, and Oceanus Procellarum. Based on the buoyancy hypothesis, any type of mare basaltic magma could have erupted within these regions, and indeed, some basalt flows are found within each of them. Furthermore, eruptions from within any of the above regions could conceivably have flowed onto adjacent terrain where the upper anorthositic crust is predicted to be present. Careful mapping of lunar lava flows via remote sensing data and crater count ages will be needed to confirm this latter suggestion.

At this point we would like to emphasize that our magma buoyancy hypothesis makes no predictions as to the volume of basalts that could have erupted wherever the upper crust is predicted to be absent - this hypothesis can only predict whether an eruption could have occurred. Thus, while the areally scant lava flows that are found within the South Pole-Aitken basin are consistent with our hypothesis, the buoyancy hypothesis by

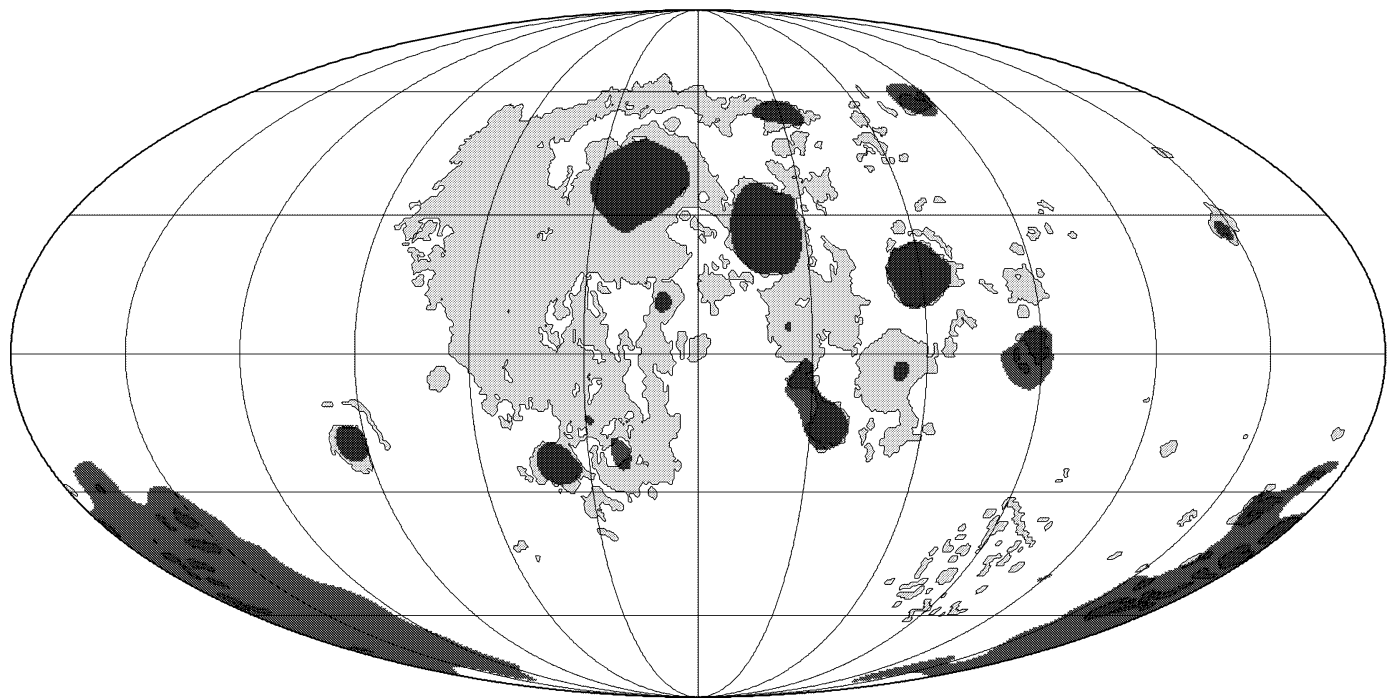

Fig. 6. Map showing the distribution of mare basalts (light gray) and regions of the Moon where the upper anorthositic crust is predicted to be less than $5 \mathrm{~km}$ thick (intermediate gray). Dark gray corresponds to an overlap of the two distributions. 
itself could not have predicted that volcanic flows would be comparatively more abundant within basins on the Moon's nearside. The volume of lava that ultimately reaches the surface is likely to be dependent upon local magma production rates and will be discussed further in Section 4.1.

Though the buoyancy hypothesis can account for the eruption of mare basalts wherever the upper crust is absent, what about those that erupted where a thick anorthositic crust is predicted to be present? The volcanic deposits that make up Oceanus Procellarum will be considered separately in Section 3.3, and here we consider those basalts that erupted within or near the Moon's farside like those of Mare Australe, Marginis and Tsiolkovsky. Gillis and Spudis [46] have determined the abundance of $\mathrm{FeO}$ and $\mathrm{TiO}_{2}$ in these and other farside lava flows using Clementine spectral reflectance data and the method of Lucey et al. [40]. While these lava flows were shown to possess moderate concentrations of $\mathrm{TiO}_{2}$, their abundances of $\mathrm{FeO}$ were found to be much lower than the nearside basalts. Using the highest mapped $\mathrm{FeO}$ and $\mathrm{TiO}_{2}$ concentrations of these lava flows (16 and $5.5 \mathrm{wt} \%$, respectively) and the empirical correlation of Fig. 5, we predict these basalts to have liquidus densities less than $2860 \mathrm{~kg} / \mathrm{m}^{3}$. This value is just lower than the expected density of the upper crust, so even though the crust in these regions of the Moon is very anorthositic in composition, all of these basalts could in principle have erupted as a result of their buoyancy alone.

\subsection{Oceanus Procellarum}

The dual-layered crustal thickness model of Wieczorek and Phillips [16] predicts that an upper anorthositic crust should be present beneath the lava flows that make up Oceanus Procellarum. Thus, based solely on a buoyancy-driven model of magma transport we might have expected that only low density basaltic magmas (those low in iron and titanium or high in aluminum) could have been able to erupt there. Unlike the mare basalts that erupted in the highlands, though, at least some of the basalts in this region have extremely high concentrations of titanium

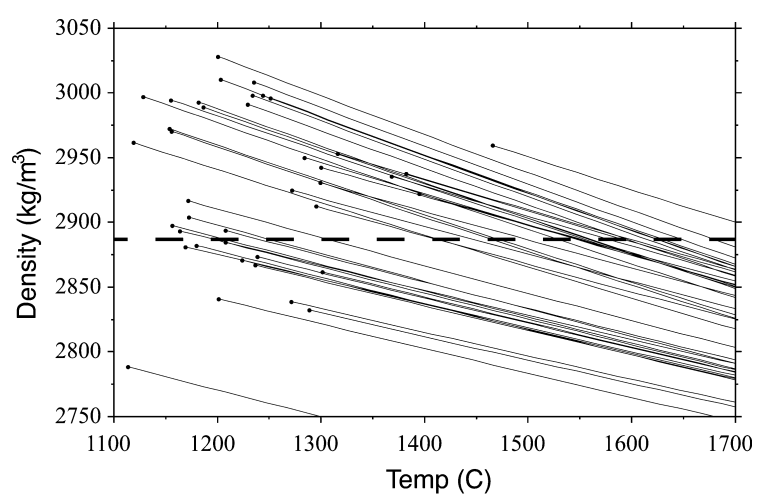

Fig. 7. Plot showing the density of mare basaltic magmas as a function of temperature. The dot at the beginning of each line corresponds to the magma's density at its liquidus temperature, and the horizontal dashed line corresponds to the density of the upper anorthositic crust.

[40] and should be relatively dense. In order to reconcile our magma buoyancy hypothesis with the dense titanium-rich basalts that are found within Oceanus Procellarum, we need to show that these magmas erupted with densities less than the underlying crust.

One possible explanation is that the crust beneath Oceanus Procellarum may be denser than that used in the dual-layered crust thickness model of Wieczorek and Phillips [16]. While acknowledging that this is a plausible hypothesis, we will not pursue this possibility in this paper. Instead, we note that if a magma were heated above its liquidus temperature, its density would decrease as a result of thermal expansion. This effect is illustrated in Fig. 7 where we have plotted the densities of the mare basaltic magmas as a function of temperature. This plot demonstrates that if these magmas were superheated to just over $1700^{\circ} \mathrm{C}$ all of them would have been less dense than the upper anorthositic crust. Furthermore, most of the basaltic magmas become buoyant in the crust at temperatures considerably less than this value.

Is it plausible to expect such high temperatures in the mantle directly beneath Oceanus Procellarum? Gamma-ray data obtained from the Lunar Prospector mission have shown that the surface abundance of KREEP is highly concentrated in the Oceanus Procellarum and Mare Imbrium re- 
gions, and this has likely influenced the thermal evolution of this region. Wieczorek and Phillips [24] have in fact shown that the enhanced heat production of this province should have been sufficient to melt the underlying mantle, giving rise to the volcanic flows that are found in this region of the Moon. Up until about 3.5 Ga, their model predicts that the top of the mantle should have had temperatures in excess of $1700^{\circ} \mathrm{C}$. This model used a conservative estimate of the quantity of heat-producing elements in this province, so these high temperatures may have existed for a longer period of time. Thus, as basaltic melts from depth buoyantly rose through the mantle they could have become heated above their liquidus temperature, decreasing their density in the process.

It has alternatively been suggested by Zhong et al. [25] that the asymmetric distribution of mare basalts on the Moon could be the result of a degree-1 upwelling of KREEP- and ilmenite-rich magma ocean cumulates. In this model, ilmenite crystallizes from a lunar magma ocean and sinks to the center of the Moon carrying with it a significant amount of heat-producing elements in the process. Because of the high density of these cumulates, they stay at the center of the Moon until they become heated enough to buoyantly rise in a large-scale degree-1 upwelling. Melting in this model occurs deep in the mantle where liquidus temperatures are about $1700^{\circ} \mathrm{C}$. Thus if these basaltic melts could rise through the overlying mantle without exchanging a significant amount of heat with their surroundings, then the superliquidus temperatures of these magmas could have offset their negative compositional buoyancy in the crust. Whether a magma can become, or remain, superheated in either of these models deserves further study and will depend upon factors such as the size of the magma diapirs and their associated ascent rate. We do note, though, that the depths and geomorphology of lunar sinuous rilles may require these features to have formed from superheated lava [47].

Even though we need to invoke special (though arguably reasonable) thermal conditions to explain the eruption of mare basalts within Oceanus Procellarum, we note that this condition may need only to have occurred at isolated locales within this province. Mapping of Eratosthenianaged lava flows within Mare Imbrium by Schaber [48] shows that one of these flows extends for about $1200 \mathrm{~km}$ in length. Comparing Clementine-derived topography with his mapping suggests that this flow was ultimately arrested by a topographic barrier. Thus, many of the basalts found within Oceanus Procellarum could have erupted from within a few isolated topographically high volcanic centers (e.g., the Aristarchus plateau, just west of Copernicus, Marius Hills, or Rümker Hills, see [17] and Fig. 1) and flowed downhill into what is now Oceanus Procellarum. An inspection of the elevation data in Fig. 1 shows that these volcanic provinces are indeed located at regionally high elevations. Since these volcanic provinces are likely to have been the sites of intense and sustained magmatic activity, it is conceivable that a large portion of the basalts within Oceanus Procellarum may have originated from within them.

\section{Discussion}

\subsection{Lateral variations in magma production}

If a certain region of the Moon were volcanically active, the magma buoyancy hypothesis could be used to predict whether a basaltic magma would erupt at the surface or form a crustal intrusion instead. However, even if this hypothesis predicts that a basaltic eruption could occur, local magma production rates will significantly influence the total volume of lava that ultimately makes it to the surface.

If our buoyancy hypothesis is correct, the South Pole-Aitken basin suggests to us that large lateral variations in magma production did indeed exist beneath the Moon's crust. Geophysical [16] and remote sensing studies [45] both suggest that a lower noritic crust is exposed in this basin, and the buoyancy hypothesis predicts that any type of mare basalt could have erupted there. Though basaltic flows are present in this basin, Fig. 1 clearly shows that they are areally scant when compared to that of the nearside. In fact if these basaltic flows were evenly spread across the floor 
of this basin $(\sim 1000 \mathrm{~km}$ radius $)$ the average thickness of this veneer (using the data of [18]) would only be about $50 \mathrm{~m}$. In contrast, the average thickness of mare basalts in Oceanus Procellarum is probably more than $400 \mathrm{~m} \mathrm{[49]} \mathrm{and} \mathrm{their}$ thickness within the large impact basins is probably much greater. Thus, this difference seems to suggest that the quantity of magma produced within the nearside mantle was about 10 times greater than that produced within the mantle of the farside. A hemispheric dichotomy in magma production is consistent with recent lunar thermal models [24-26].

\subsection{The existence of shallow mare basaltic plutonic rocks}

In our discussion of the magma buoyancy hypothesis we have thus far assumed that the lunar crust was unfractured. However, the seismic profiles obtained beneath the Apollo 12 and 14 landing sites show that the seismic velocity there gradually increases in the crust from the surface to a depth of $20 \mathrm{~km}$, and this has been interpreted as a result of impact-induced fractures closing with increasing lithostatic pressure (e.g., [13]). Though the reduction in density of the crust due to this fracturing has not been quantitatively assessed from the seismic data, investigations of the terrestrial Ries impact crater offer some insight into the magnitude of this effect. From modeling this crater's negative Bouguer gravity anomaly, the in situ density reduction of the upper $0.25 \mathrm{~km}$ of the crust has been inferred to be about $400 \mathrm{~kg} /$ $\mathrm{m}^{3}$ [50] At about $2 \mathrm{~km}$ depth the density is inferred to have been reduced by only $100 \mathrm{~kg} / \mathrm{m}^{3}$, and below $6 \mathrm{~km}$ depth fractures within the bedrock are inferred to be nearly closed or absent.

If the magnitude of fracturing beneath the Ries crater is applicable to the Moon, then the density of the top $1.5 \mathrm{~km}$ of the crust could have densities as low as 2500 and $2700 \mathrm{~kg} / \mathrm{m}^{3}$ for anorthositic and noritic crustal materials, respectively. (Since the increase of lunar lithostatic pressure with depth is about six times less than that of the Earth, closure of fractures within the lunar crust will occur at comparatively greater depths.) All of the mare basaltic magmas in Fig. 4 are denser than these values, so one might naively think that this would invalidate our premise that a magma must be less dense than the surrounding crust in order to erupt. Once magma stalls at a shallow neutral buoyancy horizon, however, an eruption may eventually occur because of two processes. First, as discussed in Section 2.3, a growing bladed dike progressively overshoots the neutral buoyancy horizon with time, and a few kilometers overshoot to reach the surface is to be expected [9]. Secondly, gas exsolution from a magma as it approaches the surface could also help in driving a basaltic eruption. If carbon monoxide is the main exsolved phase, then this process should be important for depths less than $4 \mathrm{~km}$ below the surface [29].

Though a low density impact-brecciated surface layer on the Moon would not likely completely inhibit a basaltic eruption from occurring, this low density layer would, nonetheless, promote the formation of near surface basaltic intrusions (most likely in the form of bladed dikes). In fact, it is quite possible that the volume of intruded magma may be much greater than that which ultimately makes it to the surface. Thus, in regions of the Moon where volcanic flows are prevalent, the near surface crust (less than about $10 \mathrm{~km}$ ) may contain a significant quantity of mare basaltic plutonic rocks. It is possible that the central peaks of complex craters that formed in volcanically active regions may sample these putative plutonic rocks.

\section{Conclusions}

Lunar basalts generally have higher concentrations of both $\mathrm{FeO}$ and $\mathrm{TiO}_{2}$ when compared to common terrestrial basalts. If the crust of the Moon were anorthositic in composition, then most of these dense magmas would not have been able to rise through it and erupt at the surface based on buoyancy considerations alone. The lunar crust, however, is widely acknowledged to become increasingly noritic (and hence denser) with depth, and our calculated liquidus densities of mare basaltic magmas show that they should be less dense than the lower portion of the crust. 
Thus, if impact processes regionally removed the upper anorthositic crust, then any type of mare basalt could have erupted there by considering only buoyancy effects.

The dual-layered crustal thickness model of Wieczorek and Phillips [16] predicts that the lower noritic crust should be exposed at the surface beneath almost all of the nearside multiring basins and the farside South Pole-Aitken basin. The basaltic eruptions that occurred in these regions are thus consistent with our hypothesis that magma buoyancy is the predominant factor controlling the eruption of basalts on the Moon. Those basalts that erupted on or close to the Moon's farside, where an upper anorthositic crust is present, have been shown to possess a low abundance of $\mathrm{FeO}$ [46] and are predicted to be less dense than the crust there. The only lunar basalts that do not neatly fit into this scenario are those that erupted within and adjacent to Oceanus Procellarum. These eruptions can be reconciled within the magma buoyancy hypothesis if these magmas erupted at superliquidus temperatures. Because of the unique thermal evolution of the Procellarum region of the Moon, this condition could have been satisfied.

If magma buoyancy is the dominant factor in controlling whether a basaltic eruption will or will not occur on the Moon, then this hypothesis has several implications. First, the paucity of lava flows in the South Pole-Aitken basin reflects a total farside magma production that is about 10 times lower than that of the nearside. And secondly, since the near surface crust of the Moon is highly fractured as a result of impact cratering, near surface mare basaltic intrusive rocks should be common within the crust wherever extrusive lava flows are found.

\section{Acknowledgements}

We thank Walter Kiefer and Lionel Wilson for thoughtful reviews of this manuscript. This research was supported by the Lunar Data Analysis Program under NASA Grant NAG5-8707 for M.A.W. and M.T.Z. R.J.P. was supported by NASA Grant NAG5-4448.[SK]

\section{References}

[1] W.M. Kaula, G. Schubert, R.E. Lingenfelter, W.L. Sjogren, W.R. Wollenhaupt, Lunar topography from Apollo 15 and 16 laser altimetry, Proc. Lunar Sci. Conf. 4th, 1973, pp. 2811-2819.

[2] S.K. Runcorn, On the origin of mascons and moonquakes, Proc. Lunar Conf. 5th, 1974, pp. 3115-3126.

[3] S.C. Solomon, Mare volcanism and lunar crustal structure, Proc. Lunar Sci. Conf. 6th, 1975, pp. 1021-1042.

[4] E. Stolper, D. Walker, Melt density and the average composition of basalt, Contrib. Mineral. Petrol. 74 (1980) 7 12.

[5] C.T. Herzberg, W.S. Fyfe, M.J. Carr, Density constraints on the formation of the continental Moho and crust, Contrib. Mineral. Petrol. 84 (1983) 1-5.

[6] M.P. Ryan, Neutral-buoyancy controlled magma transport and storage in mid-ocean ridge magma reservoirs and their sheeted-dike complex: a summary of basic relationships, in: M.P. Ryan (Ed.), Magmatic Systems, Academic Press, San Diego, CA, 1994, pp. 97-138.

[7] G.P.L. Walker, Gravitational (density) controls on volcanism, magma chambers and intrusions, Aust. J. Earth Sci. 36 (1989) 149-165.

[8] A.M. Rubin, D.D. Pollard, Origins of blade-like dikes in volcanic rift zones, in: R.W. Decker, T.L. Wright, P. Stauffer (Eds.), Volcanism in Hawaii, U.S. Geol. Surv. Prof. Paper, 1987, pp. 1449-1470.

[9] J.R. Lister, Buoyancy-driven fluid fracture: similarity solutions for the horizontal and vertical propagation of fluid-filled cracks, J. Fluid Mech. 217 (1990) 213-239.

[10] J.R. Lister, R.C. Kerr, Fluid-mechanical models of crack propagation and their application to magma transport in dykes, J. Geophys. Res. 96 (1991) 10,049-10,077.

[11] M.T. Zuber, P.J. Mouginis-Mark, Caldera subsidence and magma chamber depth of the Olympus Mons volcano, Mars, J. Geophys. Res. 97 (1992) 18,295-18,307.

[12] J.W. Head, L. Wilson, Lunar mare volcanism: Stratigraphy, eruption conditions, and the evolution of secondary crusts, Geochim. Cosmochim. Acta 56 (1992) 21552175 .

[13] M.N. Toksöz, A.M. Dainty, S.C. Solomon, K.R. Anderson, Structure of the Moon, Rev. Geophys. 12 (1974) 539-567.

[14] M.T. Zuber, D.E. Smith, F.G. Lemoine, G.A. Neumann, The shape and internal structure of the Moon from the Clementine mission, Science 266 (1994) 1839-1843.

[15] G.A. Neumann, M.T. Zuber, D.E. Smith, F.G. Lemoine, The lunar crust: Global structure and signature of major basins, J. Geophys. Res. 101 (1996) 16841-16843.

[16] M.A. Wieczorek, R.J. Phillips, Potential anomalies on a sphere: Applications to the thickness of the lunar crust, J. Geophys. Res. 103 (1998) 1715-1724.

[17] D.E. Wilhelms, The geologic history of the Moon, U.S. Geol. Surv. Spec. Paper 1348, 1987.

[18] R.A. Yingst, J.W.I. Head, Volumes of lunar lava ponds in South Pole-Aitken and Orientale basins: Implications for 
eruption conditions, transport mechanisms, and magma source regions, J. Geophys. Res. 102 (1997) 10909-10931.

[19] P.G. Lucey, P.D. Spudis, M. Zuber, D. Smith, E. Malaret, Topographic-compositional units on the Moon and the early evolution of the lunar crust, Science 266 (1994) 1855-1858.

[20] D.J. Lawrence, W.C. Feldman, B.L. Barraclough, A.B. Binder, R.C. Elphic, S. Maurice, M.C. Miller, T.H. Prettyman, Thorium abundances on the lunar surface, J. Geophys. Res. 105 (2000) 20307-20331.

[21] L.A. Haskin, The Imbrium impact event and the thorium distribution at the lunar highlands surface, J. Geophys. Res. 103 (1998) 1679-1689.

[22] B.L. Jolliff, J.J. Gillis, L. Haskin, R.L. Korotev, M.A. Wieczorek, Major lunar crustal terranes: Surface expressions and crust-mantle origins, J. Geophys. Res. 105 (2000) 4197-4216.

[23] R.L. Korotev, The great lunar hot spot and the composition and origin of the Apollo mafic ('LKFM') impactmelt breccias, J. Geophys. Res. 105 (2000) 4317-4345.

[24] M.A. Wieczorek, R.J. Phillips, The Procellarum KREEP terrane: implications for mare volcanism and lunar evolution, J. Geophys. Res. 105 (2000) 20417-20430.

[25] S. Zhong, E.M. Parmentier, M.T. Zuber, A dynamic origin for the global asymmetry of lunar mare basalts, Earth Planet. Sci. Lett. 177 (2000) 131-140.

[26] E.M. Parmentier, S. Zhong, M.T. Zuber, On the relationship between chemical differentiation and lunar magmatic asymmetries (abstract), in: Lunar Planet. Sci. XXXI (CDROM), Lunar and Planetary Institute, Houston, TX, 2000, p. abstract 1614 .

[27] D.E. Smith, M.T. Zuber, G.A. Neumann, F.G. Lemoine, Topography of the Moon from Clementine lidar, J. Geophys. Res. 102 (1997) 1591-1611.

[28] A.S. Konopliv, A.B. Binder, L.L. Hood, A.B. Kucinskas, W.L. Sjogren, J.C. Williams, Improved gravity field of the Moon from Lunar Prospector, Science 281 (1998) 14761480.

[29] L. Wilson, J.W. Head III, Ascent and eruption of basaltic magma on the Earth and Moon, J. Geophys. Res. 86 (1981) 2971-3001.

[30] J. Longhi, Experimental petrology and petrogenesis of mare volcanics, Geochim. Cosmochim. Acta 56 (1992) 2235-2251.

[31] G. Hulme, A review of lava flow processes related to the formation of lunar sinuous rilles, Geophys. Surv. 5 (1982) 245-279.

[32] Basaltic Volcanism Study Project (BVSP), Basaltic Volcanism on the Terrestrial Planets, Pergamon Press, Tarrytown, NY, 1981.

[33] J.W. Delano, Buoyancy-driven melt segregation in the Earth's Moon, I, Numerical results, Proc. Lunar Planet. Sci. Conf. 20th, 1990, pp. 3-12.

[34] R.A. Lange, I.S.E. Carmichael, Densities of $\mathrm{Na}_{2} \mathrm{O}-\mathrm{K}_{2} \mathrm{O}-$ $\mathrm{CaO}-\mathrm{MgO}-\mathrm{FeO}-\mathrm{Fe}_{2} \mathrm{O}_{3}-\mathrm{Al}_{2} \mathrm{O}_{3}-\mathrm{TiO}_{2}-\mathrm{SiO}_{2}$ liquidus: new measurements and derived partial molar properties, Geochim. Cosmochim. Acta 51 (1987) 2931-2946.

[35] R.A. Robie, B.S. Hemingway, Thermodynamic Properties of Minerals and Related Substances at 298.15 K and 1 Bar Pressure and at Higher Temperatures, USGS Bull. 2131 (1995) $461 \mathrm{pp}$.

[36] V.C. Kress, I.S.E. Carmichael, The compressibility of silicate liquids containing $\mathrm{Fe}_{2} \mathrm{O}_{3}$ and the effect of composition, temperature, oxygen fugacity and pressure on their redox states, Contrib. Mineral. Petrol. 108 (1991) 82-92.

[37] Y. Bottinga, D.F. Weill, The viscosity of magmatic silicate liquids: a model for calculation, Am. J. Sci. 272 (1972) 438-475.

[38] J.W. Delano, Pristine lunar glasses: criteria, data, and implications, Proc. Lunar Planet. Sci. Conf. 16th, Part 2, J. Geophys. Res. 91 (1986) D201-D213.

[39] C.M. Pieters, Mare basalt types on the front side of the Moon, Proc. Lunar Planet. Sci. Conf. 9th, 1978, pp. 2825-2849.

[40] P.G. Lucey, D.T. Blewett, B.R. Hawke, Mapping the FeO and $\mathrm{TiO}_{2}$ content of the lunar surface with multispectral imagery, J. Geophys. Res. 103 (1998) 3679-3699.

[41] M.A. Wieczorek, R.J. Phillips, The structure and compensation of the lunar highland crust, J. Geophys. Res. 102 (1997) 10933-10943.

[42] A.M. Reid, A.R. Duncan, S.H. Richardson, In search of LKFM, Proc. Lunar Sci. Conf. 8th, 1977, pp. 2321-2338.

[43] D.B.J. Bussey, P.D. Spudis, Compositional studies of the Orientale, Humorum, Nectaris, and Crisium lunar basins, J. Geophys. Res. 105 (2000) 4235-4243.

[44] S. Tompkins, C.M. Pieters, Mineralogy of the lunar crust: Results from Clementine, Meteorit. Planet. Sci. 34 (1999) 25-41.

[45] C.M. Pieters, S. Tompkins, J.W. Head, P.C. Hess, Mineralogy of the mafic anomaly in the South Pole-Aitken Basin: implications for excavation of the lunar mantle, Geophys. Res. Lett. 24 (1997) 1903-1906.

[46] J.J. Gillis, P.D. Spudis, Inventory of $\mathrm{FeO}$ and $\mathrm{TiO}_{2}$ compositions for mare deposits on the far side of the Moon (abstract), in: Lunar Planet. Sci. XXIX (CD-ROM), Lunar and Planetary Institute, Houston, TX, 1998, p. abstract 1521 .

[47] D.A. Williams, S.A. Fagents, R. Greeley, A reassessment of the emplacement and erosional potential of turbulent, low-viscosity lavas on the Moon, J. Geophys. Res. 105 (2000) 20189-20205.

[48] G.G. Schaber, Lava flows in Mare Imbrium: geologic evaluation from Apollo orbital photography, Proc. Lunar Sci. Conf. 4th, 1973, pp. 73-92.

[49] R.A. De Hon, Thickness of the western mare basalts, Proc. Lunar Planet. Sci. Conf. 10th, 1979, pp. 2935-2955.

[50] J. Pohl, D. Stöffler, H. Gall, K. Ernstson, The Ries impact crater, in: D.J. Roddy et al. (Eds.), Impact and Explosion Cratering, Pergamon Press, New York, 1977, pp. 343-404. 